\title{
Pin1 modulates the structure and function of human RNA polymerase II
}

\author{
Yu-Xin Xu, ${ }^{1}$ Yutaka Hirose, ${ }^{2}$ Xiao Zhen Zhou, ${ }^{3}$ Kun Ping Lu, ${ }^{3}$ and James L. Manley ${ }^{1,4}$ \\ ${ }^{1}$ Department of Biological Sciences, Columbia University, New York, New York 10027, USA; ${ }^{2}$ Department of Molecular \\ and Cellular Biology, Kanazawa University, Kanazawa 920-0934, Japan; ${ }^{3}$ Department of Medicine, Beth Israel Deaconess \\ Medical Center, Harvard Medical School, Boston, Massachusetts 02215, USA
}

\begin{abstract}
The C-terminal domain of the RNA polymerase (RNAP) II largest subunit (CTD) plays critical roles both in transcription of mRNA precursors and in the processing reactions needed to form mature mRNAs. The CTD undergoes dynamic changes in phosphorylation during the transcription cycle, and this plays a significant role in coordinating its multiple activities. But how these changes themselves are regulated is not well understood. Here we show that the peptidyl-prolyl isomerase Pin1 influences the phosphorylation status of the CTD in vitro by inhibiting the CTD phosphatase FCP1 and stimulating CTD phosphorylation by cdc2/cyclin B. This is reflected in vivo by accumulation of hypophosphorylated RNAP II in pin1 ${ }^{-/-}$cells, and of a novel hyper-hyperphosphorylated form in cells induced to overexpress Pin1. This hyper-hyperphosphorylated form of RNAP II also accumulates in M-phase cells, in a Pin1-dependent manner, and associates specifically with Pin1. Functionally, we find that Pin1 overexpression specifically inhibits ongoing transcription of mRNA precursors in vivo and both transcription and RNAP II-stimulated pre-mRNA splicing in cell extracts. Pin1 thus plays a significant role in regulating RNAP II CTD structure and function.
\end{abstract}

[Keywords: Pin1; RNA polymerase II; RNAP II CTD; RNA splicing; transcription; prolyl isomerase]

Received July 22, 2003; revised version accepted September 17, 2003.

The multisubunit RNA polymerase II (RNAP II) has long been known to be responsible for transcription of mRNA-encoding genes. More recently, it has become clear that the enzyme participates in posttranscriptional events as well (for review, see Hirose and Manley 2000; Maniatis and Reed 2002; Orphanides and Reinberg 2002). Key to all these functions is the CTD (C-terminal domain), which consists in mammals of 52 tandem repeats of the consensus heptapeptide YSPTSPS. The CTD can be extensively phosphorylated, especially at the Ser 2 and Ser 5 positions, which results in two distinguishable forms of RNAP II, the hypophosphorylated IIA and hyperphosphorylated IIO (for review, see Dahmus 1996). RNAP IIA is preferentially recruited to promoters during the formation of the transcription preinitiation complex, in which the CTD contributes to the response to different signals from activators or repressors (Myers and Kornberg 2000). The transition from initiation to elongation is accompanied by CTD phosphorylation, predominantly on Ser 5 by the CDK7 component of the general transcription factor TFIIH (Komarnitsky et al. 2000; Schroeder et al. 2000). During elongation, the phosphorylation pattern changes toward Ser 2 phosphorylation (Cho et al. 2001). This involves distinct cyclin-dependent kinases, such as the CDK9 subunit of the elongation factor p-TEFb (Price 2000). Although several

${ }^{4}$ Corresponding author.

E-MAIL JLM2@columbia.edu; FAX (212) 865-8246.

Article published online ahead of print. Article and publication date are at http://www.genesdev.org/cgi/doi/10.1101/gad.1135503.
CTD kinases have been identified, only one CTD phosphatase, FCP1, has been characterized (Chambers and Dahmus 1994; Cho et al. 1999). FCP1 presumably helps to recycle RNAP II at the end of the transcription cycle by converting RNAP IIO into IIA for another round of transcription.

The involvement of RNAP II, and specifically its phosphorylated CTD, in splicing of mRNA precursors is supported by several studies (see Manley 2002 and references therein). For example, mRNA precursors synthesized in transiently transfected cells by an RNAP II with a truncated CTD are inefficiently spliced (McCracken et al. 1997). Splicing can also be significantly stimulated in vitro in the absence of transcription by purified RNAP IIO, but not IIA, which in fact inhibits splicing (Hirose et al. 1999). Splicing stimulation during transcription may involve two mechanistic phases. First, the interaction of splicing factors with CTD-associated factors facilitates recognition of splice sites on the nascent pre-mRNA. For instance, the elongation factor TAT-SF1 can recruit splicing factors, including snRNPs, to the nascent RNAs during in vitro transcription, and this interaction was found not only to stimulate splicing but also to promote transcription elongation (Fong and Zhou 2001). Second, the CTD likely participates directly in the assembly of the spliceosome by interacting with specific splicing factors. An interesting example is provided by Prp40, an evolutionarily conserved component of U1 snRNP (KaO and Siliciano 1996; Neubauer et al. 1997), which interacts with the phosphorylated CTD via a proline-recognizing WW domain (Morris and Greenleaf 2000). 
The coordinated assembly and disassembly of both transcription and RNA processing machineries would appear to require a flexible and dynamic CTD structure. The structural flexibility of the CTD is suggested by recent crystal structure of RNAP II, even though the structure of the CTD was not resolved (Cramer et al. 2001). The CTD is located near the exit point of the nascent transcript from the body of the polymerase, and a linker sequence, which could serve to provide important flexibility, connects the CTD. Once the nascent transcript emerges from RNAP II, it would be easily accessible to factors assembled on the CTD. Thus, regulation of CTD structure could be an important aspect in mRNA production. Because the CTD undergoes dynamic changes in phosphorylation during transcription, such regulation could be modulated by changes in phosphorylation and/ or dephosphorylation. Unique to the CTD is not only the tandem heptad repeats, but also the presence of multiple SP dipeptides, which constitute a conserved phosphorylation motif important in many cellular processes. Significantly, cis-trans isomerization of prolyl peptide bonds is known to be a rate-limiting step in protein folding (Fisher 1994). The multiple repeats of the SP motif suggest that reconfiguration of the CTD may involve additional factors to catalyze peptidyl-prolyl isomerization. One candidate for this is the peptidyl-prolyl isomerase Pin1, which has a specificity for phosphorylated S/T-P dipeptides (Yaffe et al. 1997).

Human Pin1 was initially identified as an evolutionarily conserved protein required for proper mitotic progression (Lu et al. 1996). Many recent studies have indicated that Pin1 functions not only in cell cycle regulation, but also in several other cellular processes (for review, see K.P. Lu et al. 2002). For instance, Pin1 can interact with transcription factors such as phosphorylated c-Jun and $\beta$-catenin and increase their activities in transcription of the cyclin D1 gene (Ryo et al. 2001; Wulf et al. 2001). The phosphorylated CTD may also be a target of Pin1, as the CTD interacts with human Pin1 in vitro (Albert et al. 1999), and with the yeast homolog of Pin1, Ess1, in vitro and in vivo (Morris et al. 1999; Wu et al. 2000). Unlike other substrates, which have only one or two SP motifs, the CTD contains multiple potential sites for Pin 1 binding and catalysis. Pin 1 colocalizes with the splicing factor SC35 (Lu et al. 1996), suggesting that Pin 1 may play a role in transcription and/or premRNA processing. Consistent with this, in Saccharomyces cerevisiae, mutation of ESS1 resulted in defects in pre-mRNA 3'-end formation (Hani et al. 1999).

In this paper, we show that the interaction of Pin 1 with the CTD modulates the phosphorylation status of the CTD. Pin 1 inhibits CTD dephosphorylation by FCP1 and stimulates its phosphorylation by $\mathrm{cdc} 2 / \mathrm{cyclinB}$ in vitro. Confirming the in vivo significance of these findings, the level of CTD phosphorylation is reduced in pin $1^{-/-}$cells, especially in $M$ phase, and inducible Pin 1 overexpression results in accumulation of a hyper-hyperphosphorylated form of RNAP II. We demonstrate dynamic phosphorylation changes of RNAP II during cell cycle progression, and show that the hyper-hyperphos- phorylated RNAP II accumulates exclusively in M phase. We also show that Pin 1 overexpression inhibits both RNAP II transcription and pre-mRNA splicing. Our data indicate that Pin 1 plays a significant role in regulating the activities of the CTD.

\section{Results}

Pin1 inhibits RNAP II CTD dephosphorylation by the CTD phosphatase FCP1

The close relationship between phosphorylation and CTD structure and function suggests that Pin 1 could play a direct role in modulating CTD function by influencing phosphorylation or dephosphorylation. In fact, genetic data in yeast as well as biochemical data point to a potential interaction among FCP1, Pin1, and RNAP II (Wu et al. 2000; Kops et al. 2002). We first wished to test the effect of Pin 1 on the ability of FCP1 to dephosphorylate the CTD, and to this end purified human Pin1 (as a GST fusion protein from Escherichia coli), human FCP1 (as an his-tagged protein from recombinant baculovirusinfected insect cells), and human RNAP IIA and RNAP IIO (from HeLa cells; see Fig. 1A). As an initial experiment, two different amounts of FCP1 were incubated with RNAP IIO in the presence or absence of increasing amounts of GST-Pin1, and CTD dephosphorylation was assayed by Western blotting with an antibody (8WG16) that detects the CTD regardless of phosphorylation status. The results (Fig. 1B) show that, as expected, FCP1 was able to convert the IIo isoform to the dephosphorylated IIa form (Fig. 1B, cf. lanes 1 and 2,6). In each case, addition of GST-Pin1 inhibited dephosphorylation (Fig. 1B, lanes 3-5,7-9). To provide evidence that the inhibition was specific, we expressed and purified two Pin1 mutant proteins as GST fusions (see Fig. 1A,C). One, Y23A, alters a key residue in the $\mathrm{N}$-terminal WW domain, which is responsible for substrate binding ( $\mathrm{Lu}$ et al. 1999), and the other, R68,69A, disrupts catalytic activity (Shen et al. 1998). These two mutant proteins, together with wild type, were then used in an experiment similar to that in Figure 1B. GST-Pin 1 again strongly inhibited dephosphorylation (Fig. 1D, cf. lanes 2,3 and 4-6). However, both mutants were defective, Y23A (Fig. 1D, lanes 7-9) partially so and R68,69A (Fig. 1D, lanes 10-12) was completely inactive. The results indicate that the interaction between Pin 1 and RNAP II inhibits dephosphorylation of the CTD by FCP1.

\section{Pin1 stimulates CTD phosphorylation by cdc2/cyclin $B$}

We next set out to investigate whether Pin 1 might also influence phosphorylation of RNAP II. Several CTD kinases have been identified, but they have different phosphorylation specificities, and function during different stages of the transcription cycle and/or under different physiological conditions (for review, see Lin et al. 2002). For example, the mitotic kinase cdc2/cyclinB can phosphorylate the CTD on both Ser 2 and Ser 5, but the significance of this is unknown (Cisek and Corden 1989; 

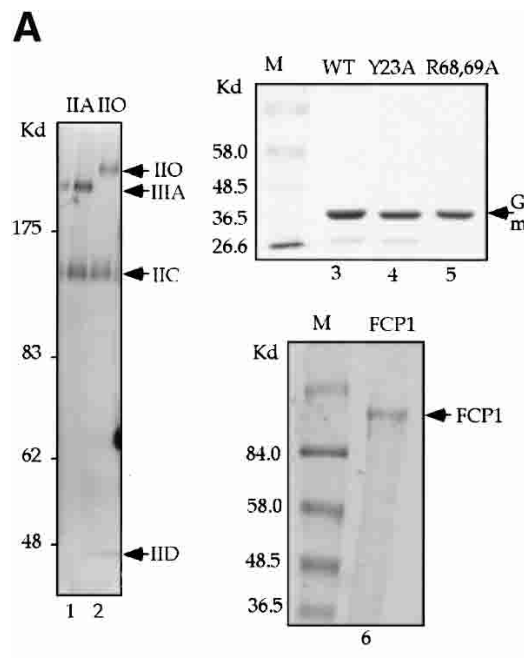

B

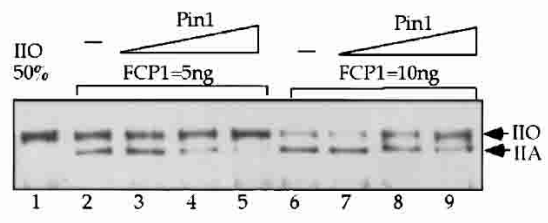

C

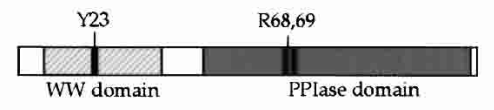

D

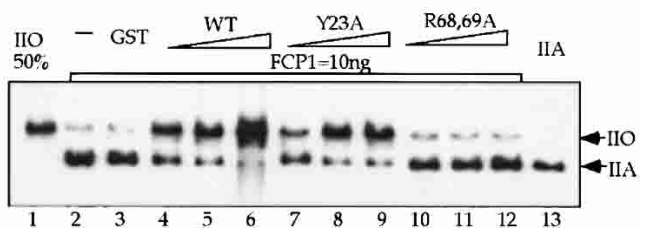

Figure 1. Dephosphorylation of RNAP IIO by FCP1 is inhibited by Pin1 in vitro. (A) Proteins used in this study. Silver staining of 7.5\% SDS-PAGE gel with RNAP IIA (lane 1) and IIO (lane 2) purified from HeLa cells. Coomassie staining of 7.5\% SDS-PAGE gel with GST-Pin1 (lane 3), GST-Pin1 Y23A (lane 4), and GST-Pin1 R68,69A (lane 5) purified from E. coli. Coomassie staining of 7.5\% SDS-PAGE gel with his-tagged FCP1 purified from recombinant baculovirus-infected SF9 cells (lane 6). Sizes of marker proteins are indicated. (B) Inhibition of RNAP IIO dephosphorylation by Pin1. Purified RNAP IIO (50 ng) was preincubated with GST-Pin1 (10, 100, $200 \mathrm{ng}$; lanes 3-5,7-9, respectively) at $30^{\circ} \mathrm{C}$ for $10 \mathrm{~min}$ followed by addition of $5 \mathrm{ng}$ (lanes 2-5) and $10 \mathrm{ng}$ (lanes 6-9) of FCP1. Reaction mixtures were incubated at $30^{\circ} \mathrm{C}$ for $20 \mathrm{~min}$. Reactions were terminated by addition of SDS loading buffer and proteins were analyzed by $7.5 \%$ SDS-PAGE. Blots were probed with mAb 8 WG16. The positions of RNAP IIA and IIO are indicated. $(C)$ Diagram of human Pinl structure. Positions of the two Pinl mutations are shown. (D) Mutation in the Pinl catalytic domain abolishes inhibition. Dephosphorylation reactions were performed as in $B$ with 10, 100, or 200 ng GST-Pin1 (lanes 4-6), GST-Pin1Y23A (lanes 7-9), or $\mathrm{R} 68,69 \mathrm{~A}$ (lanes 10-12). Reaction mixtures were incubated at $30^{\circ} \mathrm{C}$ for $30 \mathrm{~min}$. The blot was probed with polyclonal antibody N20.

Gebara et al. 1997). Given the fact that Pin1 is a known mitotic regulator, we reasoned that there could be a link between Pin1 and cdc2 in modulating phosphorylation of the CTD during, or as cells enter, M phase. To examine the potential role of Pin 1 in controlling CTD phosphorylation by cdc2/cyclin B, we first used purified RNAP IIA as a substrate. Because Pin1 binding is phosphorylation-dependent, there is no detectable interaction between Pin 1 and RNAP IIA (Morris et al. 1999; data not shown). However, once cdc2 begins to phosphorylate the CTD, the partially phosphorylated CTD can be recognized by Pin1, and this interaction could possibly affect subsequent phosphorylation. To test this, RNAP IIA was incubated with purified recombinant cdc2/cyclin B in the presence of increasing amounts of GST-Pin1 or the R68,69A mutant. As expected, cdc2/ cyclin B phosphorylated the IIa subunit, as observed by the mobility change compared with the input IIa (Fig. 2A, cf. lanes 2 and 3,4). Strikingly, addition of GST-Pin1 stimulated phosphorylation (Fig. 2A, lanes 5-7), but Pin1 R68,69A was without effect (Fig. 2A, lanes 8-10). Similar results were obtained in a direct phosphorylation assay using $\left[\gamma^{-32} \mathrm{P}\right] \mathrm{ATP}$ (Fig. 2B). Incorporation of ${ }^{32} \mathrm{P}$ into RNAP IIa was stimulated by GST-Pin1 (Fig. 2B, lanes 4-6) but not by the R68,69A mutant (Fig. 2B, lanes 7-9). The data suggest that binding of Pinl to newly phosphorylated sites enhances subsequent CTD phosphorylation.
We next tested whether Pin1 might also stimulate phosphorylation of RNAP IIO by cdc2/cyclin B. Although RNAP IIO is considered to be hyperphosphorylated, it can be further phosphorylated, on both Ser 2 and Ser 5, and indeed such a hyper-hyperphosphorylated form accumulates in M-phase cells (see below). To investigate the possible effect of Pin1 on RNAP IIO CTD phosphorylation, purified RNAP IIO was preincubated with or without GST-Pin1 or the R68,69A mutant followed by addition of cdc2/cyclin B. CTD phosphorylation was monitored by Western blotting with $\mathrm{H} 5$ and H14 antibodies, which allow detection of Ser 2 and Ser 5 phosphorylation, respectively (Fig. 2C,D, respectively). The RNAP IIo subunit CTD was, indeed, further phosphorylated, on both Ser 2 and Ser 5 (Fig. 2C,D, cf. lanes 2 and 3,4). Most importantly, GST-Pin1 significantly stimulated phosphorylation on Ser 2 and Ser 5 in a dosedependent manner (Fig. 2C,D, lanes 4-6), whereas the R68,69 mutant was essentially without effect (Fig. 2C,D, lanes 7-9). Thus our data together indicate that Pin1 can enhance CTD phosphorylation in vitro both by inhibition of FCP1-mediated dephosphorylation and by increasing phosphorylation by cdc2/cyclin B.

\section{Pin1 modulates RNAP II CTD phosphorylation in vivo}

The above results indicate that Pin 1 has the potential to modulate RNAP II phosphorylation levels. But it was 

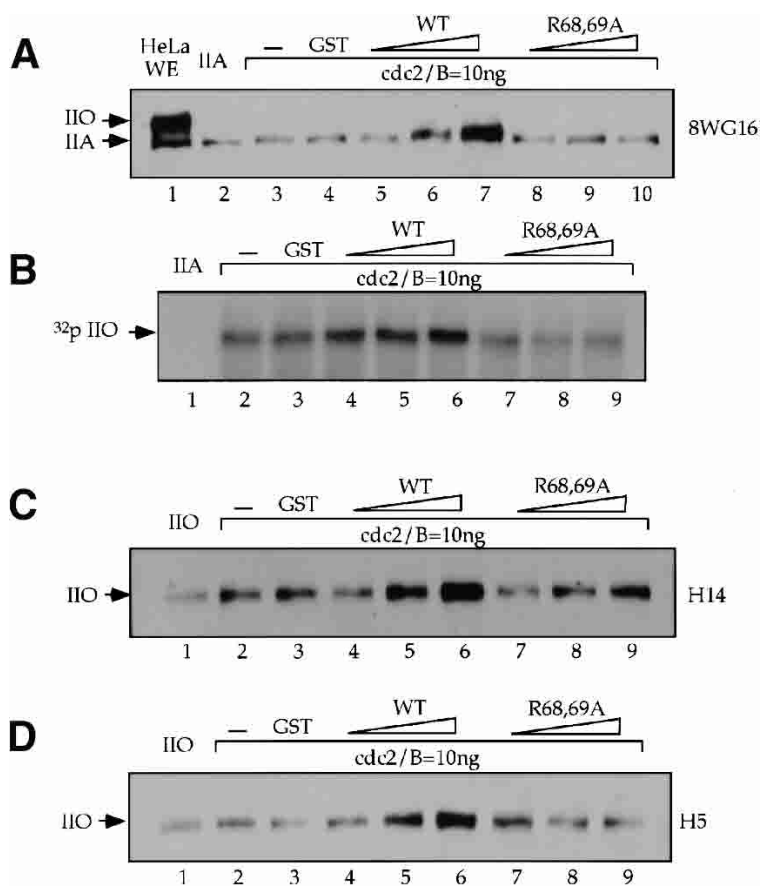

Figure 2. Pin 1 stimulates RNAP II phosphorylation by cdc2/ cyclin B in vitro. (A) Purified RNAP IIA (20 ng) was incubated with $200 \mathrm{ng}$ GST (lane 4), GST-Pin1 and GST-Pin1 R68,69A (10, $100,200 \mathrm{ng}$; lanes 5-7,8-10, respectively) in the presence of $\operatorname{cdc} 2 /$ cyclin $\mathrm{B}$ at $30^{\circ} \mathrm{C}$ for $30 \mathrm{~min}$. Reactions were terminated by addition of SDS loading buffer and proteins analyzed by $7.5 \%$ SDS-PAGE. (Lane 1) HeLa whole-cell extract $(5 \mu \mathrm{g})$. Blots were probed with mAb 8WG16. Positions of RNAP IIA and IIO are indicated. $(B)$ Reactions were performed as in $A$, but with $20 \mu \mathrm{Ci}$ $\left[\gamma^{-32} \mathrm{P}\right] \mathrm{ATP}$ at $30^{\circ} \mathrm{C}$ for $20 \mathrm{~min} .(C)$ Purified RNAP IIO $(20 \mathrm{ng})$ was preincubated with GST (lane 3), Pin1 and R68,69A mutant $\left(10,100,200 \mathrm{ng}\right.$; lanes 4-6,7-9, respectively) at $30^{\circ} \mathrm{C}$ for $10 \mathrm{~min}$, followed by addition of $10 \mathrm{ng}$ of cdc2/cyclin B. Mixtures were incubated at $30^{\circ} \mathrm{C}$ for $30 \mathrm{~min}$. Reactions were terminated by addition of SDS loading buffer, and proteins were analyzed by $7.5 \%$ SDS-PAGE. The blot was probed with mAb H14. The positions of RNAP IIO are indicated. $(D)$ Reactions were performed as in $C$, but probed with mAb $\mathrm{H} 5$.

important next to determine whether this actually occurs in vivo. To this end, we first examined the phosphorylation status of RNAP II, by Western blotting, under conditions in which Pin 1 was inactivated. If a function of Pin 1 is to reduce FCP1 activity and to increase cdk activity toward the CTD, then the amount of RNAP IIO should decrease in the absence of Pin 1 activity. We initially asked whether incubation of cells with the Pin 1 inhibitor juglone affected RNAP IIO accumulation in HeLa cells. The results (Fig. 3A) reveal a concentrationdependent increase in gel mobility and decrease in the amount of the IIo subunit, as expected if Pin 1 is inhibited and therefore unable to down-regulate FCP1 and/or up-regulate CTD kinase activities. Note that the amount of RNAP IIa did not increase correspondingly, suggesting that the excess unphosphorylated IIa subunit was degraded. To examine more directly the role of Pin 1 in determining RNAP II phosphorylation levels, we used mouse embryonic fibroblasts (MEFs) derived from pin1 $1^{-/-}$mice (Liou et al. 2002). We first compared the phosphorylation status (i.e., gel mobility) of the IIo subunit in wild-type and mutant MEFs and for comparison in NIH 3 T3 cells (Fig. 3C). As in the juglone-treated cells, the IIo isoform detected in the pin $1^{-/-}$cells displayed significantly greater gel mobility than that in either of the other two cell lines (Fig. 3C, lanes 1-3). Strongly supporting the possibility that the effect of juglone on RNAP II phosphorylation was mediated by Pin1, wildtype MEFs displayed a similar decrease in RNAP IIo accumulation in response to juglone as observed in HeLa cells (Fig. 3B, lanes 6-10), but RNAP IIo in the pin1 $1^{-1-}$ MEFs was unaffected by the inhibitor (Fig. 3B, lanes 1-5).

To extend these findings, we next examined RNAP II phosphorylation status in cells overexpressing Pin1. To this end, HeLa cells were stably transfected with plas-

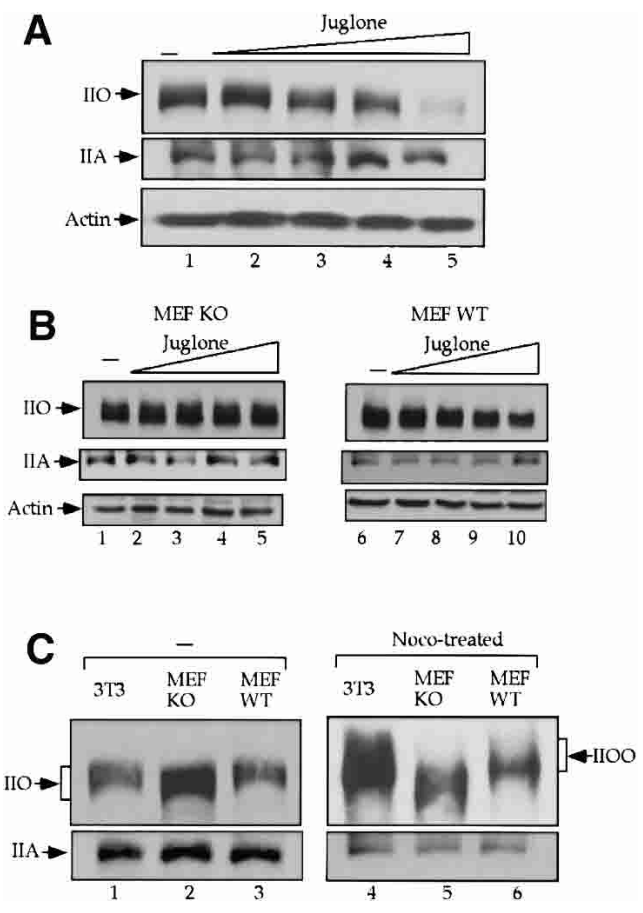

Figure 3. Pin 1 enhances RNAP II phosphorylation in vivo. $(A)$ The Pin 1 inhibitor juglone decreases RNAP II phosphorylation. HeLa cells were treated with juglone for $8 \mathrm{~h}(0.05,0.125,0.625$, $1.25 \mu \mathrm{M}$, lanes 2-5). Total cell lysates were separated by $7.5 \%$ SDS-PAGE, and blots were probed with mAb H14 (upper), 8WG16 (middle), and anti-actin antibody (lower). (B) RNAP II phosphorylation levels in pin1 $1^{-/-}$MEFs are unaffected by juglone. pin1-/- (right panel) and wild-type (left panel) MEFs were treated with juglone $(0.05,0.125,0.625,1.25 \mu \mathrm{M}$, lanes 2-5,710 , respectively) for $8 \mathrm{~h}$. Total cell lysates were separated by $7.5 \%$ SDS-PAGE and probed with mAbs H5 and H14 (upper), mAb 8WG16 (middle), and anti-actin (bottom). The positions of RNAP IIA/O and actin are indicated. $(C)$ Western blot analysis of total cell lysates from NIH 3T3 cells (lanes 1,4) and pin $1^{-1-}$ (lanes 2,5) and wild-type (lanes 3,6) MEFs, in the absence (lanes $1-3$ ) or presence of $100 \mathrm{ng} / \mathrm{mL}$ nocodazole for $12 \mathrm{~h}$ (Nocotreated; lanes 4-6). Equivalent amounts $(\sim 5 \mu \mathrm{g})$ of the lysates were separated by $7.5 \%$ SDS-PAGE and probed with mAb H14 (upper panel) and mAb 8WG16 (lower panel). 
mids expressing flu epitope-tagged wild-type or R68,69A Pin1 from a minimal tetracycline (tet)-responsive promoter and a tet-activatable tet-VP16 fusion protein. Cell lysates were prepared at different times after addition of doxycycline and analyzed by Western blotting, first with $\mathrm{H} 14$ antibodies. The results show that as flu-Pin 1 levels increased (Fig. 4A, top), the amount of the IIo subunit appeared to increase, and its mobility decreased (Fig. 4A, bottom). At the same time, RNAP IIa levels decreased, consistent with its conversion to IIo. At the longest time of induction (19 h), flu-Pin1 levels declined, probably because of toxicity, and, significantly, so did levels of hyperphosphorylated RNAP IIo. In contrast, Pin1 R68,69A expression had no detectable effect on RNAP II phosphorylation even though it was expressed at least as well as wild-type Pin1 (Fig. 4B). Pin1-induced RNAP II hyperphosphorylation also occurred on Ser 2, because enhanced phosphorylation was detected in Western blots probed with H5 antibodies (Fig. 4A). It is noteworthy, however, that Ser 5 phosphorylation appears to contrib-
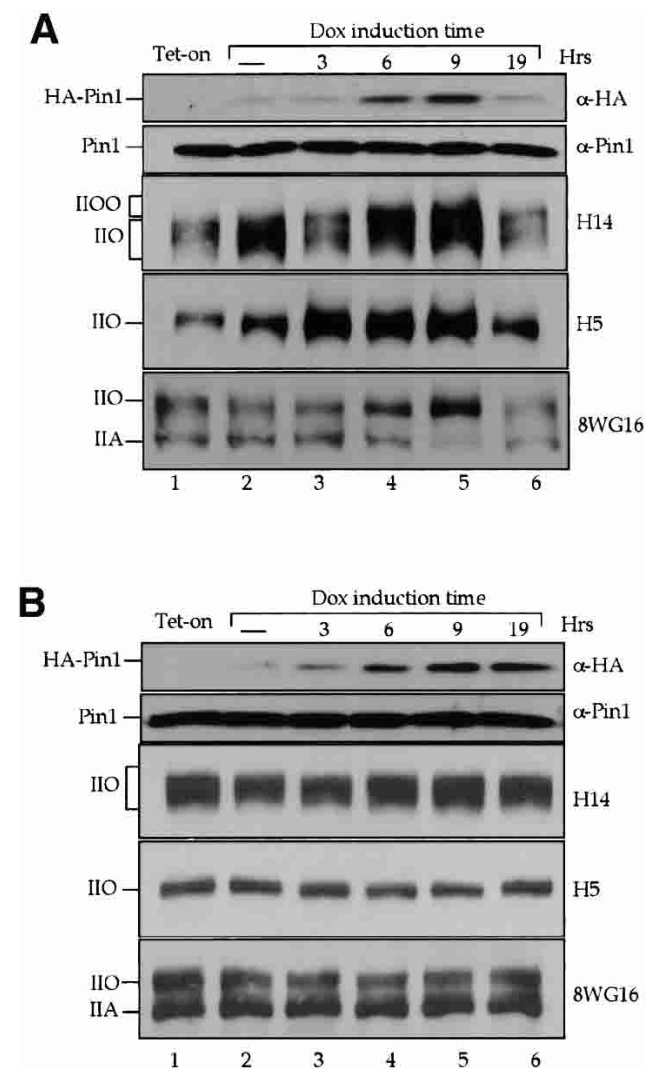

Figure 4. Inducible overexpression of Pin 1 increases RNAP IIO hyperphosphorylation in vivo. (A) HeLa cells stably expressing inducible flu-tagged Pin1 were cultured in the absence (lane 2) or presence (lanes 3-6) of $1 \mu \mathrm{g} / \mathrm{mL}$ doxycycline, and total cell lysates were prepared at the times indicated. Lysates were also prepared from the parental (tet-on, lane 1) cells. Proteins were fractionated by $7.5 \%$ SDS-PAGE, and blots were probed with $\alpha$-flu and anti-Pin1 antibodies, and $\mathrm{mAb} \mathrm{H14,} \mathrm{H5,} \mathrm{and} \mathrm{8WG16}$ (from top to bottom, respectively). Flu-Pin1, Pin1, and RNAP IIO and IIA are indicated. (B) Similar experiments as in $A$ but using cells inducibly expressing R68,69 Pin1. ute more to the reduced mobility of RNAP IIo (see below). Taken together, our results indicate that Pin 1 helps to determine the phosphorylation status of RNAP II in vivo.

\section{Pin1-dependent RNAP II hyperphosphorylation occurs} during $M$ phase

Pin1 was initially identified as a potential mitotic regulator, and considerable data support the idea that this is, indeed, an important aspect of its function (K.P. Lu et al. 2002). We therefore wished to investigate whether the Pin1-dependent hyperphosphorylation of RNAP II we detected might be heightened in $M$ phase. To this end, we first assessed the phosphorylation status of RNAP II at different stages of the cell cycle, again by Western blotting. An initial experiment examined HeLa cells arrested by a double thymidine block at G1/S phase and then released, allowed to continue through the cell cycle and to accumulate in $\mathrm{M}$ phase. Cell lysates were probed first with the 8WG16 antibody to detect both the IIo and IIa isoforms (Fig. 5A, top). Strikingly, not only did the amount of IIo appear to increase, but more significantly, its mobility decreased in the lysates from cells accumulated in $M$ phase (Fig. 5A, lanes 9,10). In contrast, the levels of IIa remained similar, except in $\mathrm{M}$ phase, where they were slightly reduced. To extend this analysis, blots from a similar experiment were probed with either $\mathrm{H} 14$ (Fig. 5A, middle panel) or H5 (Fig. 5A, bottom panel). The H14 blot shows a striking accumulation and mobility change of the hyperphosphorylated IIo subunit, consistent with the analysis with 8 WG16, whereas the H5 blot revealed almost no accumulation of this hyperphosphorylated form. Together, these results indicate that RNAP II becomes very highly phosphorylated during M phase, and that this occurs principally on Ser 5. Although a form of RNAP II that appears to possess an intermediate level of CTD phosphorylation has been described (RNAPIIm; Bonnet et al. 1999), such a hyperhyperphosphorylated form of RNAP II has not, and we refer to it as RNAP IIOO.

We next wished to determine whether the M-phasespecific hyperphosphorylation was dependent on Pin 1 activity. A first experiment extended the analysis of the pin1 $1^{-/-}$MEFs to examine IIo phosphorylation in lysates from mitotic (nocadazole-treated) cells. The results (Fig. 3C, lanes 4-6) reveal first that the IIo subunit from mitotic wild-type cells (3T3 and MEFs) displayed reduced mobility relative to that from asynchronous cells (Fig. $3 \mathrm{C}$, cf. lanes 1 and 4, 3 and 6), consistent with the results obtained with HeLa cells (Fig. 3C). Most striking, however, was the significant underphosphorylation (i.e., lack of hyperphosphorylation) of the IIo subunit from the nocodazole-arrested pin $1^{-/-}$MEFs (Fig. 3C, lane 5). These results indicate that Pin 1 is necessary for M-phase-specific hyperphosphorylation of the RNAP II CTD. This likely reflects its effects on FCP1 and cde2/cyclinB, although additional factors may also be involved.

The above results strongly suggest that Pin 1 interacts with RNAP IIO in vivo, as it does in vitro. To examine 
Xu et al.

A

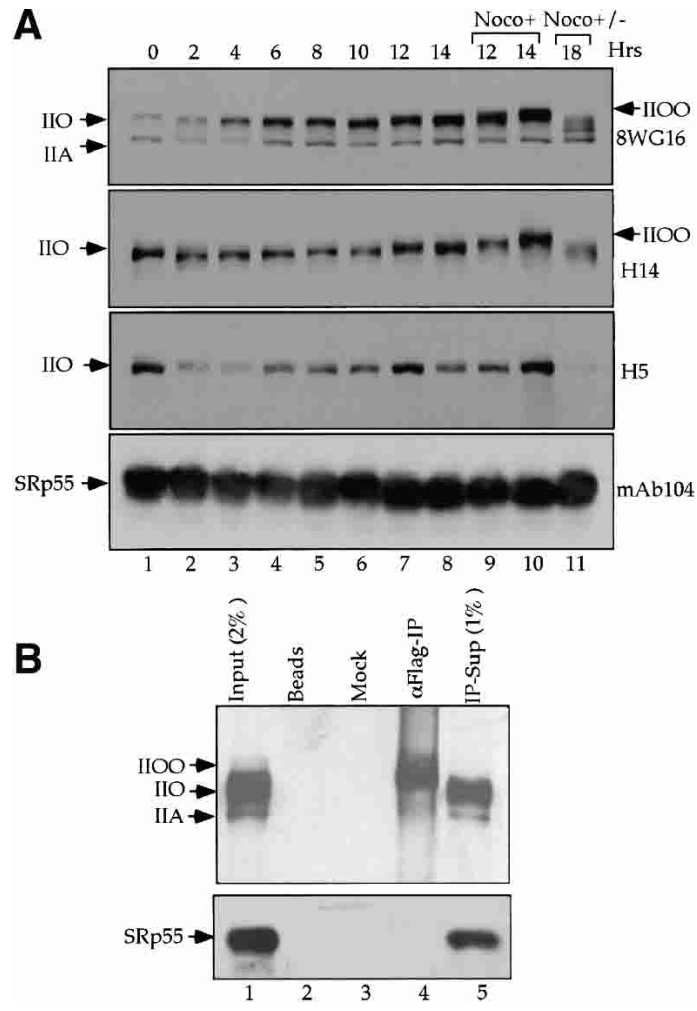

Figure 5. Hyperphosphorylated RNAP IIO accumulates in M phase and preferentially associates with Pin1. (A) HeLa cells were arrested at the G1/S boundary and then released. Nocodazole was added $8 \mathrm{~h}$ after release, and cells were incubated for another 4 or $6 \mathrm{~h}(\mathrm{Noco}+$, lanes 9,10). G1 cells (Noco+/-, lane 11) were obtained by washing the nocodazole-treated cells $(6 \mathrm{~h})$ and incubating in media without nocodazole for another $4 \mathrm{~h}$. At the indicated time points, cells were harvested and total cell lysates were fractionated by $7.5 \%$ SDS-PAGE. Blots were probed with mAb 8WG16 (upper), H14 (middle), H5 (lower), and anti-SR protein mAb104 (bottom). The positions of RNAP IIO and IIA are indicated. $(B)$ HeLa cells were transfected with an expression vector encoding Flag-epitope-tagged Pin1. Cell extracts were prepared after $48 \mathrm{~h}$. Aliquots were then immunoprecipitated with anti-Flag $\mathrm{mAb}$ (lane 4), anti-mouse $\operatorname{IgG}$ (lane 3), and protein-A-conjugated beads alone (lane 2). Pellets were washed, dissolved in sample buffer, and fractionated by $7.5 \%$ SDS-PAGE. Blots were probed with mAbs 8 WG16 plus $\mathrm{H} 14$ (upper) and $\mathrm{mAb}$ 104 (lower).

this directly, we performed coimmunoprecipitation (coIP) experiments to assess the association between the two proteins. HeLa cells were transiently transfected with an expression vector encoding Flag-epitope-tagged Pin1, and extracts were prepared and immunoprecipitated with anti-Flag antibodies. Blots were probed with $8 \mathrm{WG} 16$ and H14 or, as a control, an anti-SR protein splicing factor antibody. The results (Fig. 5B) show that a significant fraction of RNAP IIO, but not RNAP IIA or SR proteins, was specifically coIPed (Fig. 5B, lane 4). Remarkably, only a very slow mobility form of the IIo subunit, which appears identical to the hyperphosphorylated mitotic form described above (RNAP IIOO), was detected. This interaction was very specific and efficient.
Only a small amount of this form could be detected in the input (Fig. 5B, lane 1), and it was absent in the IP flowthrough (Fig. 5B, lane 5) but recovered in high yield in the IP (Fig. 5B, lane 4). Together these results indicate that not only is Pin1 required for M-phase-specific accumulation of a hyperphosphorylated form of RNAP IIO, but also that this likely reflects a strong and specific interaction between the two proteins.

\section{Pin1 inhibits RNAP II transcription in vivo}

We next wished to investigate possible functional consequences of Pin1-dependent hyperphosphorylation of RNAP II. Gene expression is known to be silenced during $M$ phase in metazoan cells, and it seemed feasible that Pin1 might contribute to this via its effect on RNAP II. To test this, we first used the Pin1-inducible cell lines described above and measured synthesis of nascent mRNAs precursors by pulse labeling following induction of wild-type or mutant Pin1. Wild-type and the R68,69A mutant Pin1-expressing cells were treated with doxycycline exactly as above, and at the indicated times cells were exposed to $\left[{ }^{3} \mathrm{H}\right]$ uridine for short pulses ( $\left.10 \mathrm{~min}\right)$. Total RNA was extracted from the cells, and, to assess mRNA transcription, poly $(\mathrm{A})^{+}$RNA was purified by oligo(dT) column chromatography. Both poly $(\mathrm{A})^{+}$RNA and the corresponding poly $(\mathrm{A})^{-}$RNA fractions were quantitated by scintillation counting and by slot blotting on membranes that were then exposed to X-ray film (see Materials and Methods for details). By both measurements, the amount of newly transcribed poly $(\mathrm{A})^{+} \mathrm{RNA}$ was significantly reduced after treatment with doxycycline in the wild-type Pin1-expressing cells (Fig. 6A, lane 1, B, lanes 1-4), whereas poly(A)- RNA synthesis was not detectably affected (Fig. 6A, lane 2, B, lanes 9-12). In contrast, both poly $(\mathrm{A})^{+}$and poly $(\mathrm{A})^{-}$RNA synthesis in the cells expressing mutant Pinl was unaffected (Fig. 6A, lanes 3,4, B, lanes 5-8,13-16). Significantly, poly(A) ${ }^{+}$ RNA synthesis increased slightly after $19 \mathrm{~h}$ of doxycycline treatment in the wild-type expressing cells, which is consistent with the observed decrease in levels of RNAP IIOO and Pin 1 at this time (see Fig. 4A). These results, coupled with our characterization of RNAP II phosphorylation in these same cells, suggest that Pin1mediated hyperphosphorylation of RNAP II leads to inhibition of mRNA synthesis.

The above experiments relied on oligo(dT) selection to identify RNAP II products. Because this, in turn, relied on efficient polyadenylation, and because Pin1 (Ess1) has been suggested to influence 3 '-end formation in yeast (Hani et al. 1999), we wished to verify the effect of Pin1 overexpression on transcription by an independent method. To this end, we prepared nuclear extracts (NE) from cells induced to express wild-type or R68,69A Pin1 for the same times indicated in Figure 4A, and assayed their transcriptional potential with a linearized plasmid containing the CMV promoter (Fig. 6C). The NEs from the cells overexpressing flu-Pin1 displayed decreased transcriptional activity as Pin 1 accumulated, but the presence of the mutant Pin1 was without effect. These 
A

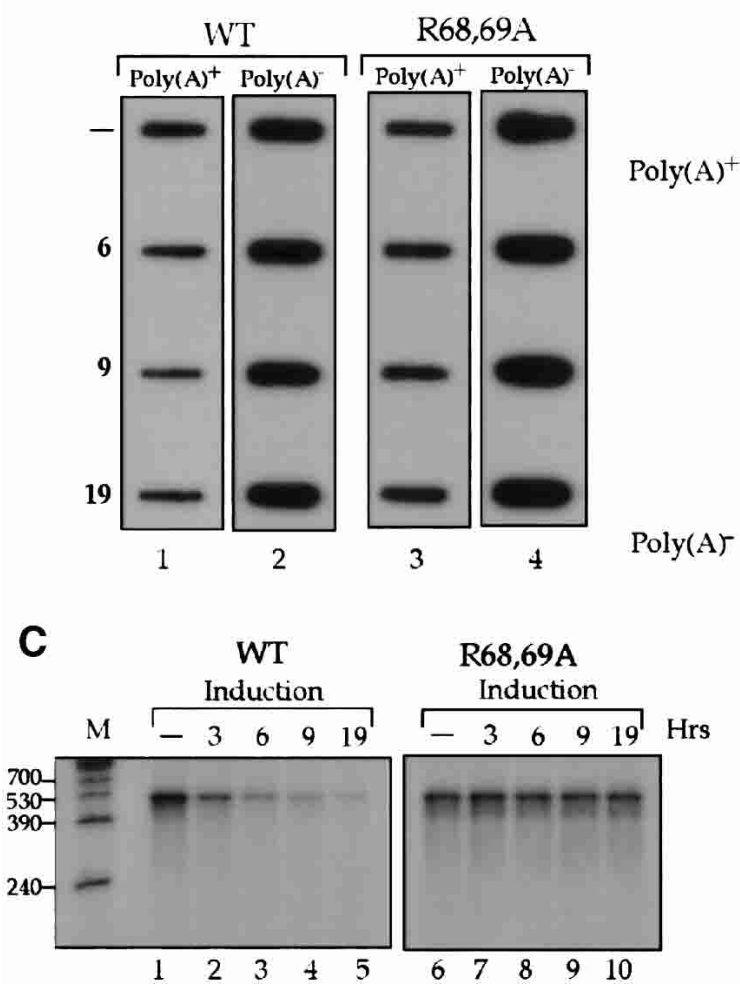

B
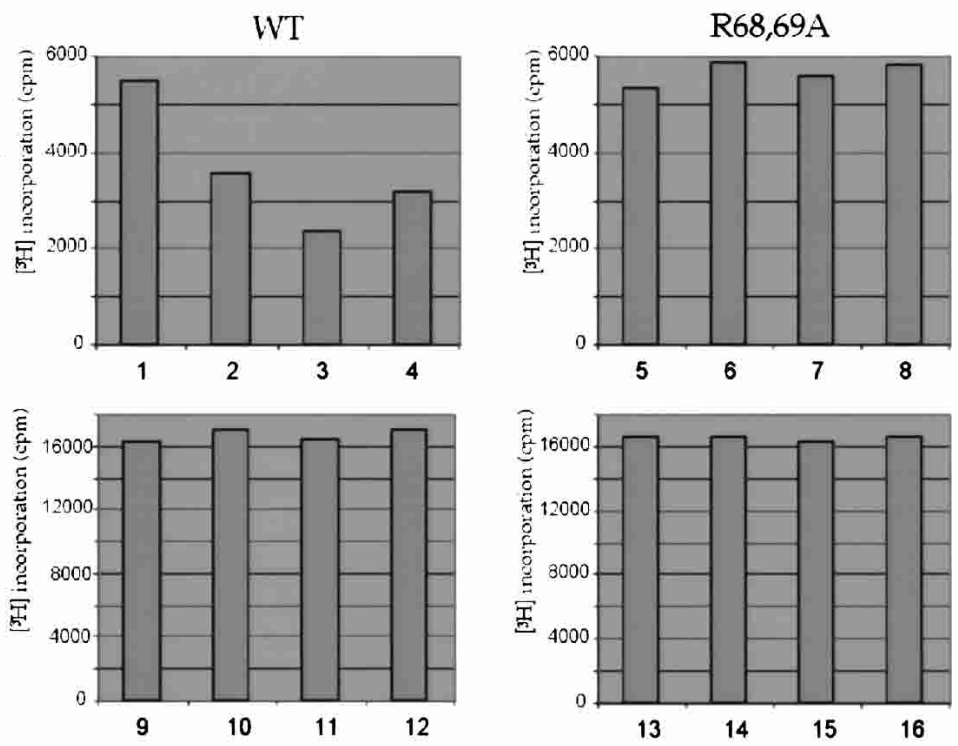

Figure 6. Inducible overexpression of Pin1 reduces RNAP II transcription in vivo and in vitro. (A) Pulse-label analysis of nascent poly(A) RNA synthesis. Wild-type and R68,69A Pin1 cell lines were incubated with or without doxycycline for the indicated times. Cells were exposed to $\left[{ }^{3} \mathrm{H}\right]$ uridine for $\sim 10 \mathrm{~min}$. Total cellular RNA was purified and poly(A) RNA was oligo(dT)-selected. Poly(A) ${ }^{+}$and poly $(\mathrm{A})^{-}$RNAs were slot-blotted, and the filter was soaked in EN3HANCE for $1 \mathrm{~h}$ and exposed to X-ray film. $(B)$ Poly(A) ${ }^{+}$and poly(A) ${ }^{-}$ RNAs from the wild-type and R68,69A cell lines as in $A$ were spotted on filters and the incorporation was determined by scintillation counting. Lanes 1-4, 5-8, 9-12, and 13-16 represent cells without and with doxycycline for 6, 9, and 19 h, respectively. (C) NEs from wild-type (right) and mutant R68,69A (left) Pin1-expressing cells with or without doxycycline treatment for the times indicated were used for in vitro transcription. A linearized CMV promoter-containing plasmid was used as template in the presence of $\left[\alpha-{ }^{32} \mathrm{P}\right] \mathrm{GTP}$ RNAs were resolved by $7 \mathrm{M}$ urea-6\% PAGE. The positions of DNA markers are indicated. The expected RNA transcript is 523 nt.

results correlate well with the accumulation of hyperphosphorylated RNAP II over the same time course (Fig. 4A), and with the inhibition observed in the in vivo pulse-label experiment, except that for unknown reasons, in vitro transcription did not recover at the 19-h time point. These results confirm that RNAP II transcription can be inhibited by Pin 1 overexpression.

\section{Pin1 inhibits pre-mRNA splicing in an RNAP II-dependent manner}

RNAP II can also function to enhance pre-mRNA splicing, and this activity requires a phosphorylated CTD. For example, we showed previously that purified RNAP IIO, but not IIA, can stimulate splicing when added to extracts lacking RNAP II (Hirose et al. 1999). To determine if Pin 1 might influence this activity, we first tested whether addition of purified recombinant Pin 1 to HeLa NE affects splicing of a model ( $\beta$-globin) pre-mRNA. The results (Fig. 7A, lanes 1-4) indicate that Pin 1 inhibited splicing in a concentration-dependent manner. Inhibition was specific, as the R68,69A mutant (Fig. 7A, lanes
5-7) did not affect splicing. Inhibition occurred at an early stage in the reaction, as analysis of spliceosome assembly showed that splicing was blocked exclusively at assembly of the A complex (Fig. 7B), which is the same step at which RNAP IIO stimulates splicing (Hirose et al. 1999).

To determine directly whether RNAP IIO might be the target of Pin 1 in splicing inhibition, we used a splicing assay dependent on RNAP IIO (Hirose et al. 1999). This involves use of HeLa S100 extract, which contains all factors required for splicing except SR proteins and also lacks RNAP II. Splicing can be activated by addition of SR proteins, and under limiting conditions, stimulated by RNAP IIO. In the presence of very low levels of the SR protein ASF/SF2, sufficient to induce only barely detectable levels of splicing (Fig. 7C, cf. lanes 1 and 2), increasing amounts of RNAP IIO significantly stimulated splicing (Fig. 7C, lanes 3-5). As with NE (Fig. 7A), addition of Pin1 effectively inhibited splicing (Fig. 7C, lanes 6-8). However, when splicing was stimulated to a comparable level solely by addition of a higher concentration of ASF/ SF2 (Fig. 7C, lane 9), addition of Pin1 was without effect 
Figure 7. Pinl inhibits RNAP II-stimulated premRNA splicing in vitro. (A) In vitro splicing of $\beta$-globin pre-mRNA in HeLa NE in the presence of increasing amounts $(10,100$, or $200 \mathrm{ng})$ of GST-Pin1 (lanes 2-4) or GST-Pin1 R68,69A (lanes 5-7). The positions of precursor RNA and splicing products are indicated. $(B)$ Spliceosome formation in NE supplemented with buffer (lanes 2-8) or 100 ng of GST-Pin1 (lanes 9-15). Reaction mixtures were incubated at $30^{\circ} \mathrm{C}$ for the times indicated. The positions of splicing complexes are indicated. $(C$, right $)$ In vitro splicing of $\beta$-globin pre-mRNA in $\mathrm{S} 100$ supplemented with limiting ASF/SF2 (12.5 ng; lane 2), ASF/SF2 plus increasing amounts of purified RNAP IIO $(5,10,20$ ng; lanes 3-5) or $20 \mathrm{ng}$ of RNAP IIO preincubated with increasing amounts of GST-Pin1 (10, 50, 100 ng; lanes 6-8). (Left) Similar splicing reaction but supplemented with $50 \mathrm{ng}$ of ASF/SF2 (lane 9) plus increasing amounts of GST-Pin $1(10,50,100$ ng; lanes $10-12)$. (D) In vitro splicing of $\beta$-globin pre-mRNA in NEs prepared from the inducible wild-type (left panel) and R68,69A (right panel) Pin1-expressing cell lines, as in Figure 6C. Cells were incubated with or without doxycycline for the indicated times. RNAs were resolved by $7 \mathrm{M}$ urea- $6 \%$ PAGE. The positions of precursor RNA and splicing products are indicated.
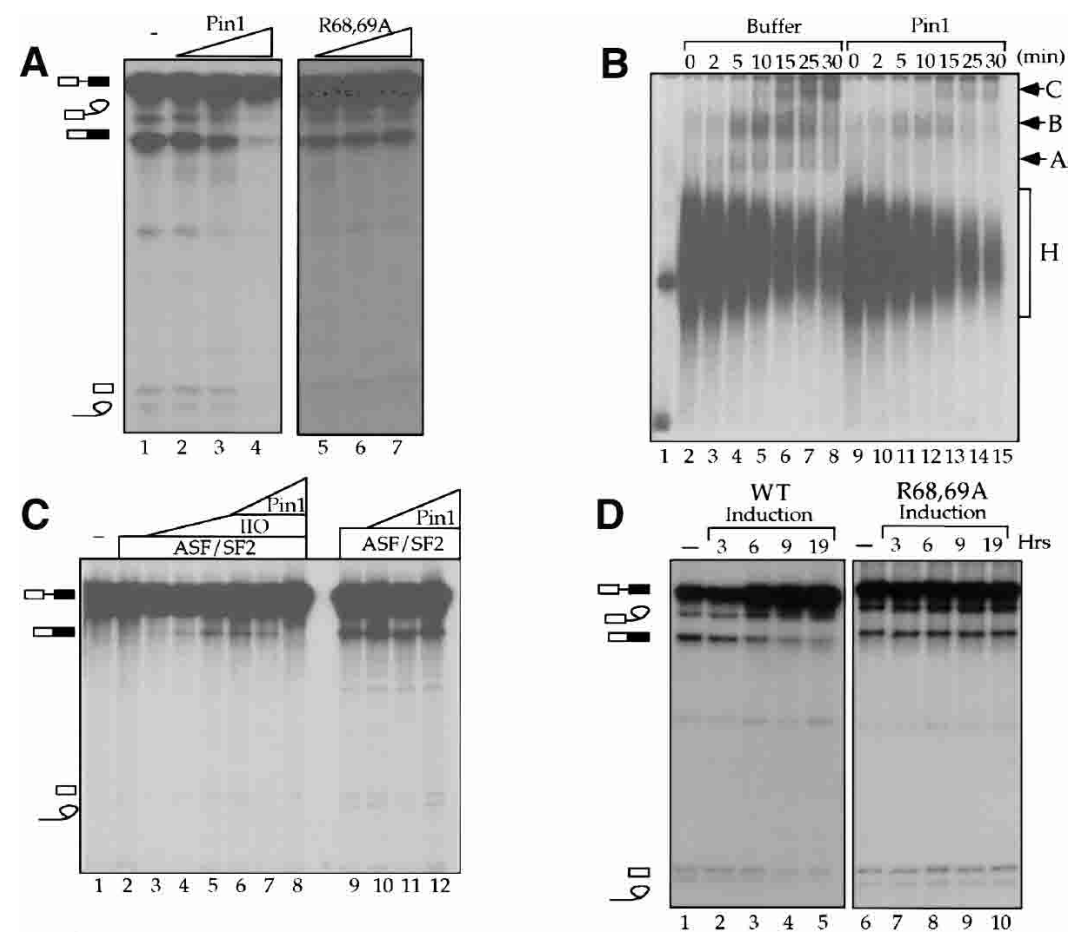

(Fig. 7C, lanes 10-12). These results indicate that Pin1 specifically inhibits splicing enhanced by RNAP IIO.

To obtain further evidence that Pin 1 can affect premRNA splicing, we again made use of the inducible Pin1 cell lines. Nuclear extracts were prepared from the wildtype and R68,69A Pin1-expressing cells after treatment with doxycycline as described above, and splicing was measured with the $\beta$-globin pre-mRNA (Fig. 7D). Splicing efficiency of NEs from the wild-type Pin1-expressing cells was reduced as time of treatment with doxycycline increased (Fig. 7D, lanes 1-5). Splicing inhibition correlated with the levels of RNAP II hyperphosphorylation, except that as with transcription splicing remained inhibited at $19 \mathrm{~h}$. In contrast, splicing efficiency was unaffected by doxycycline treatment in NEs prepared from the R68,69A Pin1-expressing cells (Fig. 7D, lanes 6-10). These results indicate that elevated Pin1 levels in cells interfere with their competence in splicing, likely via effects on RNAP II phosphorylation.

\section{Discussion}

The data presented here provide biochemical and genetic evidence that Pinl helps to control the phosphorylation status of the RNAP II CTD. We also showed that, in addition to the known phosphorylation changes of the CTD during the transcription cycle, the CTD undergoes significant phosphorylation changes during cell cycle progression. Specifically, we found that a hyperphosphorylated form of RNAP II, RNAP IIOO, accumulates in M-phase cells in a Pin1-dependent manner. Pin1 overexpression is sufficient to induce the formation of RNAP
IIOO, and this likely underlies the observed inhibition of both transcription and splicing. Our data support a model in which elevated Pin 1 activity induces RNAP IIO hyperphosphorylation, and this represses RNAP II function in both transcription and pre-mRNA splicing.

Pin1 appears to have numerous substrates, including many proteins phosphorylated in $\mathrm{M}$ phase (for review, see K.P. Lu et al. 2002). This is in keeping with its role as a mitotic regulator, and our results are consistent with this property. Gene expression is known to be silenced during mitosis in metazoan organisms, and our data suggest that Pin 1 contributes to this by stimulating hyperphosphorylation, and hence inactivation, of RNAP II. But our finding that this reflects direct inhibition of FCP1 activity and stimulation of cdc2/cyclin B activity toward the CTD points to a novel mechanism whereby Pin1 not only inhibits dephosphorylation but also activates phosphorylation of a substrate. Exactly how this occurs is unknown, but it is consistent with previous findings showing that Pin 1 often regulates the function of its substrate via multiple mechanisms leading to the same consequences. Well-studied examples include a mitotic phosphatase, cdc25c (e.g., Zhou et al. 2000; Stukenberg and Kirschner 2001) and a G1 cyclin, cyclin D1 (Wulf et al. 2001; Liou et al. 2002). Cdc25c contains a cluster of more than a dozen SP dipeptides at its $\mathrm{N}$ terminus that are targets for at least two mitotic kinases, cdc2/cyclin B and plk (Izumi and Maller 1993; Kumagai and Dunphy 1996). As with the CTD, Pin 1 binds to phosphorylated cdc25c and can have different effects on its activity. One is interference with the activity of the phosphatase PP2a, which naturally dephosphorylates 
cdc25c (Lee et al. 1991). This may involve stoichiometric interaction between cdc25c and Pin 1, which could block access to PP2a (Zhou et al. 2000; Stukenberg and Kirschner 2001), and/or catalytically alter cdc25c phosphatase activity even in the absence of PP2a (Stukenberg and Kirschner 2001). Significantly, the response to Pin1 in vitro can vary depending on the phosphorylation status of cdc $25 \mathrm{c}$ : If the phosphatase was phosphorylated by cdc2 alone, then its activity is inhibited by Pin1. But if it was phosphorylated by both cdc 2 and plk, then its activity is enhanced (Stukenberg and Kirschner 2001). These findings illustrate how a substrate can respond to Pin 1 in different ways, and thus the ability of Pinl to both increase phosphorylation and decrease dephosphorylation of the CTD is not unreasonable. This would allow the cell to turn off the function of the phosphorylated CTD with high efficiency and precise timing during mitosis.

The CTD has a remarkable, even unique, primary structure that makes it an exceptional and unusual target for Pin1. Whereas other characterized substrates typically have a small cluster of phosphorylatable S/T-P dipeptides, the CTD has from 50 (in yeast) to $>100$ (in mammals) stretched out in an essentially linear array. Given this complexity, it has not been possible to elucidate exactly which of these $\mathrm{S} / \mathrm{T}$ residues, or even how many, are phosphorylated at different times. All that is really known is that the pattern changes during the transcription cycle (e.g., Komarnitsky et al. 2000; Cho et al. 2001). Pinl may, on the one hand, help facilitate such changes, for example, by isomerizing a specific prolylpeptide bond and thereby enhancing phosphorylation of nearby $\mathrm{S}, \mathrm{T}$, or even Y residues. On the other hand, Pin 1 could be affected by these changes in phosphorylation so that the effects of Pin 1 binding and/or catalysis may change, analogous to the simpler situation observed with cdc25c. One example may be provided by earlier results suggesting that Pin1, or its yeast homolog ESS1, can in fact stimulate CTD phosphorylation by FCP1. Kops et al. (2002) used a biochemical assay to show a modest stimulation of dephosphorylation of an in vitro phosphorylated GST-CTD fusion protein, whereas genetic studies in yeast indicated that overexpression of FCP1 could rescue a lethal Ess 1 mutation (Wu et al. 2000). These results could reflect different phosphorylation states of the CTD such that Pin 1 has a positive effect on FCP1 activity as opposed to the negative effect we reported here. There are, however, alternative explanations. First, it may be that the use of GST-CTD phosphorylated in vitro (as opposed to purified RNAP IIO) together with a mixture of yeast and human proteins (Kops et al. 2002) may have produced results that differ from the in vivo situation, and the genetic effects in yeast need not reflect direct interactions. A second and more intriguing possibility is that the interaction involving the three proteins has different consequences in yeast and mammals, stimulating dephosphorylation in the former and repressing it in the latter. This could reflect the fact that the yeast CTD is half the size of the mammalian CTD, and lacks the sequence divergence found in the C-terminal half of the mammalian CTD. Teleologically, because yeast cells do not silence gene expression in M phase, there is no need to inhibit RNAP II activity, and in fact this would likely be detrimental.

Our experiments have shown that overexpression of Pin 1 can be deleterious to cell growth. In addition to the effects on gene expression we documented, HeLa cells overexpressing wild-type but not mutant Pin1 were difficult to isolate and maintain, could only produce modestly elevated, unstable levels of Pin1, and displayed somewhat reduced growth rates (data not shown). It is interesting to contrast these properties with those of other cells reported to overexpress Pin1. These include various cancer tissues and transformed cell lines, including a derivative of a breast cancer cell line (MCF-7) capable of inducibly expressing exogenous Pin1 (Ryo et al. 2001; Wulf et al. 2001). These cells do not appear to display properties of the Pin1-overexpressing cells we described. Although this could reflect any of multiple differences between these cell types, one interesting possibility reflects the fact that a proposed critical Pin 1 target protein, $\beta$-catenin, which plays a significant role in activating genes such as cyclin D1 that are involved in transformation, is not expressed in HeLa cells (Denk et al. 1997). Perhaps under these conditions, the inhibitory effects we have documented here, which would otherwise play a significant role only in mitosis, are dominant.

A subpopulation of RNAP II is located in 20-50 nuclear bodies called speckles, which contain both transcription and pre-mRNA processing factors (Lamond and Spector 2003). However, speckles are not the active site either for transcription or RNA processing; instead, they appear to be storage sites for components of the transcription and RNA processing machineries. In actively transcribing cells, RNAP II is dispersed in the nucleoplasm, but in transcriptionally inactive cells it localizes preferentially in the speckles (Zeng et al. 1997). RNAP II in speckles is highly phosphorylated and can be recognized by both $\mathrm{H} 5$ and H14 antibodies (Bregman et al. 1995), and importantly, is not transcriptionally active (Zeng et al. 1997). To maintain highly phosphorylated RNAP II in nuclear speckles likely requires additional factors, because FCP1 also appears to be located in these domains (Huang and Spector 1996). Significantly, Pin1 has been shown to colocalize with the splicing factor SC35, a marker for speckles (Lu et al. 1996), indicating that Pin 1 has the potential to play a role in maintaining high levels of RNAP II phosphorylation in these domains.

The Pin1-dependent formation of RNAP IIOO in Mphase cells provides evidence that Pin 1 plays a role in controlling RNAP II activity during mitosis. It is well known that transcription is inhibited during $M$ phase, and in the case of RNAP II this involves phosphorylation of components of the general transcription factors TFIID and TFIIH (Akoulitchev and Reinberg 1998; Long et al. 1998). It has also been observed that RNAP IIO accumulates at the expense of IIA (Akoulitchev and Reinberg 1998), which would contribute to inhibition of new rounds of transcription, as IIA is the initiating form of 
RNAP II. However, elongation is also blocked, and elongating polymerases are released, during $M$ phase (Shermoen and O'Farrell 1991; Parsons and Spencer 1997). As the IIO isoform is the elongating form of the enzyme, we suggest that the IIOO form reflects a totally inactive, M-phase-specific isoform. In keeping with this, it is intriguing that IIOO is characterized by excessive Ser 5 phosphorylation. As mentioned above, Ser 5 phosphorylation naturally decreases as elongation proceeds. In addition, structural studies suggest that Pin1, via its WW domain, preferentially interacts with Ser 5 (Verdecia et al. 2000), consistent with our observation that Ser 5 is preferentially overphosphorylated in RNAP IIOO. Our model suggests that Pin 1 activity should be elevated in $M$ phase. Although Pin1 levels do not change during the cell cycle (Shen et al. 1998), Pin1 undergoes dephosphorylation in $\mathrm{M}$ phase, which may reflect removal of an inhibitory phosphate in the WW domain (P.J. Lu et al. 2002).

The inhibition of RNAP IIO-stimulated splicing by Pin1 also likely reflects the silencing of gene expression that occurs during $M$ phase. We have recently shown that splicing, like all other steps in metazoan gene expression, is repressed in extracts of mitotic cells (Shin and Manley 2002). This inhibition requires a newly characterized SR protein, SRp38, but a role for RNAP II, and Pin1, is also consistent with available data. RNAP IIO is not an essential splicing factor, but appears to play an important stimulatory role. An attractive model is that RNAP IIO functions to recruit splicing factors to sites on nascent RNAs to facilitate cotranscriptional splicing, and that elevated Pin1 activity prevents these interactions. Although it will be important in the future to determine whether it is Pin1 binding, catalytic activity, or both that is responsible for its effects on RNAP II, our results indicate that Pinl plays a significant role in modulating gene expression at multiple levels via its interaction with RNAP IIO.

\section{Materials and methods}

Protein purification and in vitro RNAP II dephosphorylation and phosphorylation assays

Purification of RNAP IIA and IIO from HeLa cells was carried out as previously described (Lu et al. 1991). Recombinant GSTPin 1 and the mutant Y23A and R68,69A were purified from $E$. coli as described (Xiao and Manley 1997). Recombinant histagged FCP1 was expressed in baculovirus-infected SF9 cells and purified as described (Cho et al. 1999). Flu-epitope-tagged cdc2/ cyclin B was purified from Sf9 insect cells coinfected with human $\mathrm{p} 34 \mathrm{cdc} 2$ and cyclin B recombinant baculovirus (Wang and Prives 1995). RNAP IIO dephosphorylation analysis was performed in buffer P containing $20 \mathrm{mM}$ HEPES (pH 7.5), $10 \mathrm{mM}$ $\mathrm{MgCl}_{2}, 1 \mathrm{mM}$ DTT, $10 \%$ glycerol, and $0.2 \mathrm{mM}$ PMSF at $30^{\circ} \mathrm{C}$ (Cho et al. 1999). RNAP II phosphorylation was conducted in a buffer containing $60 \mathrm{mM} \mathrm{KCl}, 50 \mathrm{mM}$ Tris $(\mathrm{pH} 7.8), 10 \mathrm{mM}$ $\mathrm{MgCl}_{2}, 0.5 \mathrm{mM}$ DTT, $1.5 \mathrm{mM}$ sodium azide, $1.5 \mathrm{mM} \mathrm{NaF}$, and $0.2 \mathrm{mM}$ PMSF at $30^{\circ} \mathrm{C}$.

\section{RNAP II phosphorylation analysis during the cell cycle}

HeLa cells were arrested at the G1/S boundary by double thymidine block, and cells were then released into the cell cycle
(Whitfield et al. 2000). To obtain pure populations of mitotic cells, nocodazole $(50 \mathrm{ng} / \mathrm{mL}$, Sigma) was added at $8 \mathrm{~h}$ after release, and cells were incubated for another $4 \mathrm{~h}$ or $6 \mathrm{~h}$. G1 cells were obtained by washing the nocodazole-treated cells $(6 \mathrm{~h})$ and incubating in media without nocodazole for another $4 \mathrm{~h}$. At the indicated time points, cells were harvested and total cell lysates were prepared in $1 \times$ SDS sample buffer. A fraction of cells from each time point was analyzed by flow cytometry using FACSCalibur (Becton Dickinson). All nocodazole-treated cells were $>85 \%$ G $2 / M$ phase.

Cell culture, total cell extract, juglone treatment, and stable Pin1 cell line

HeLa, NIH3T3 cells, and pin $1^{-/-}$and wild-type MEFs were cultured in DMEM supplemented with 10\% FBS. Total cell extracts were prepared by solubilizing the cells in TD buffer containing $1 \%$ Triton $\mathrm{X}-100,50 \mathrm{mM}$ Tris- $\mathrm{HCl}(\mathrm{pH} 7.5), 250 \mathrm{mM}$ $\mathrm{NaCl}, 5 \mathrm{mM}$ EDTA, $50 \mathrm{mM}$ sodium fluoride, and protease inhibitor cocktail (Sigma). Extracts were rocked for $15 \mathrm{~min}$, then centrifuged at $14,000 \mathrm{rpm}$ at $4^{\circ} \mathrm{C}$ for $15 \mathrm{~min}$. HeLa, pin $1^{-/-}$, and wild-type MEF cells were treated with the indicated concentrations of juglone (Sigma) at $37^{\circ} \mathrm{C}$ for $8 \mathrm{~h}$, and total cell extracts were prepared in TD buffer. The flu-tagged Pin 1 constructs were generated by subcloning wild-type and R68,69A mutant Pin1 cDNA into the pTRE-HA plasmid. Tet-on cells were generated by transfecting HeLa cells with a pTet-on plasmid expressing a fusion protein of reverse Tet repressor and VP-16 activation domain (Gossen and Bujard 1995). Stable cell lines inducibly expressing Pin 1 were obtained by cotransfecting Tet-on cells with pTRE-HA-Pin 1 plasmid and a pTK-Hyg selection plasmid. Cells were cultured in DMEM media containing $10 \%$ tet-free FBS (Clontech). Expression of wild-type and mutant Pin1 was induced by addition of $1 \mu \mathrm{g} / \mathrm{mL}$ doxycycline to the media for appropriate times.

\section{Immunoprecipitation}

A plasmid expressing Flag-tagged Pin 1 was generated by subcloning Pin 1 cDNA into the plasmid p3Xflag-CMV. HeLa cells were transfected with $10 \mu \mathrm{g}$ of the plasmid by calcium phosphate precipitation and after $48 \mathrm{~h}$, total cell extract was prepared in TD buffer. Anti-Flag mAb, or anti-mouse IgG was coupled to protein A-agarose beads at $4^{\circ} \mathrm{C}$ for $12 \mathrm{~h}$. After washing, beads were incubated with extract in $500 \mu \mathrm{L}$ of TD buffer at $4^{\circ} \mathrm{C}$ for 40 min, washed four times, and then resuspended in SDS loading buffer and fractionated by SDS-PAGE. Proteins were detected by Western blotting.

In vitro transcription, splicing, and spliceosome formation

Nuclear extract was prepared from HeLa cells $\left(\sim 3 \times 10^{7}\right)$ as previously described (Kleiman and Manley 2001). Cytoplasmic S100 was prepared and His-tagged ASF/SF2 was purified from baculovirus-infected SF9 cells as described (Tacke and Manley 1995). In vitro transcription was carried out in a buffer containing $20 \mathrm{mM}$ HEPES (pH 7.9), 10\% glycerol, $50 \mathrm{mM} \mathrm{KCl,} 3 \mathrm{mM}$ $\mathrm{MgCl}_{2}, 0.5 \mathrm{mM}$ DTT, $0.2 \mathrm{mM}$ EDTA, rNTP mixture $(400 \mu \mathrm{M}$ ATP; $400 \mu \mathrm{M}$ CTP; $400 \mu \mathrm{M}$ UTP; $16 \mu \mathrm{M}$ GTP, and $10 \mu \mathrm{Ci}$ $\left.\left[\alpha-{ }^{32} \mathrm{P}\right] \mathrm{GTP}\right)$ in the presence of $\sim 20 \mu \mathrm{g}$ of NE protein and $100 \mathrm{ng}$ of DNA template (a p3Xflag-CMV derivative linearized with BamHI). Reaction mixtures were incubated at $30^{\circ} \mathrm{C}$ for $60 \mathrm{~min}$. Reactions were terminated by adding stop solution containing $0.3 \mathrm{M}$ Tris- $\mathrm{HCl}(\mathrm{pH} 7.5), 0.3 \mathrm{M}$ sodium acetate, $0.5 \%$ SDS, 2 $\mathrm{mM}$ EDTA, and $3 \mu \mathrm{g} / \mathrm{mL}$ tRNA, and then were extracted with 
phenol and chloroform. Splicing reactions with NE or S100 supplemented with ASF/SF2 and purified RNAP IIO and spliceosome assembly assays were performed essentially as described (Hirose et al. 1999). RNA products were analyzed by denaturing PAGE.

\section{Pulse labeling and poly (A) RNA purification}

Wild-type and mutant Pin1-expressing cell lines were grown in media with or without doxycycline $(1 \mu \mathrm{g} / \mathrm{mL})$ for the times indicated in the figures. After adjusting the cell concentration $\left(\sim 10^{6} / \mathrm{mL}\right)$, cells were pulse-labeled with $50 \mu \mathrm{Ci} / \mathrm{mL}\left[{ }^{3} \mathrm{H}\right]$ uridine (NEN) for $\sim 10 \mathrm{~min}$ for each cell culture. Total RNAs were isolated with Trizol and poly $(\mathrm{A})^{+} \mathrm{RNA}$ was purified by oligo(dT) selection (Oligotex, QIAGEN). The poly(A) $)^{+/-}$RNAs were slotblotted onto Nylon filters. Filters were soaked in liquid scintillation cocktail for $1 \mathrm{~h}$, and then exposed to X-ray film. Incorporation of $\left[{ }^{3} \mathrm{H}\right]$ uridine in RNA was also quantitated by scintillation counting using a Micro-Betaplate reader.

\section{Acknowledgments}

We are grateful to $S$. Kaneko for purified RNAP IIO, A.D. Reinberg for the FCP1-expressing baculovirus, J. Prasad for ASF/SF2, and K. Ryan for help in the early stages of the study. We thank I. Boluk for help preparing the manuscript. This work was supported by NIH grants GM37971 to J.L.M. and GM58556 to K.P.L.

The publication costs of this article were defrayed in part by payment of page charges. This article must therefore be hereby marked "advertisement" in accordance with 18 USC section 1734 solely to indicate this fact.

\section{References}

Akoulitchev, S. and Reinberg, D. 1998. The molecular mechanism of mitotic inhibition of TFIIH is mediated by phosphorylation of CDK7. Genes \& Dev. 12: 3541-3550.

Albert, A., Lavoie, S., and Vincent, M. 1999. A hyperphosphorylated form of RNA polymerase II is the major interphase antigen of the phosphoprotein antibody MPM-2 and interacts with the peptidyl-prolyl isomerase Pin1. I. Cell Sci. 112: 2493-2500.

Bonnet, F., Vigneron, M., Bensaude, O., and Dubois, M.F. 1999. Transcription-independent phosphorylation of the RNA polymerase II C-terminal domain (CTD) involves ERK kinases (MEK1/2). Nucleic Acids Res. 27: 4399-4404.

Bregman, D.B., Du, L., van der Zee, S., and Warren, S.L. 1995. Transcription-dependent redistribution of the large subunit of RNA polymerase II to discrete nuclear domains. J. Cell Biol. 129: 287-298.

Chambers, R.S. and Dahmus, M.E. 1994. Purification and characterization of a phosphatase from HeLa cells which dephosphorylates the C-terminal domain of RNA polymerase II. J. Biol. Chem. 269: 26243-26248.

Cho, H., Kim, T.K., Mancebo, H., Lane, W.S., Flores, O., and Reinberg, D. 1999. A protein phosphatase functions to recycle RNA polymerase II. Genes \& Dev. 13: 1540-1552.

Cho, E.J., Kobor, M.S., Kim, M., Greenblatt, J., and Buratowski, S. 2001. Opposing effects of Ctk1 kinase and Fcp1 phosphatase at Ser 2 of the RNA polymerase II C-terminal domain. Genes \& Dev. 15: 3319-3329.

Cisek, L.J. and Corden, J.L. 1989. Phosphorylation of RNA polymerase by the murine homologue of the cell-cycle control protein cdc2. Nature 339: 679-684.

Cramer, P., Bushnell, D.A., and Kornberg, R.D. 2001. Structural basis of transcription: RNA polymerase II at $2.8 \AA$ resolution. Science 292: 1863-1876.

Dahmus, M.E. 1996. Reversible phosphorylation of the C-terminal domain of RNA polymerase II. I. Biol. Chem. 271: 19009-19012.

Denk, C., Hulsken, J., and Schwarz, E. 1997. Reduced gene expression of E-cadherin and associated catenins in human cervical carcinoma cell lines. Cancer Lett. 120: 185-193.

Fisher, G. 1994. Peptidyl-prolyl cis/trans isomerase and their effectors. Angew Chem. Int. Ed. Engl. 33: 1415-1436.

Fong, Y.W. and Zhou, Q. 2001. Stimulatory effect of splicing factors on transcriptional elongation. Nature 414: 929-933.

Gebara, M.M., Sayre, M.H., and Corden, J.L. 1997. Phosphorylation of the carboxy-terminal repeat domain in RNA polymerase II by cyclin-dependent kinases is sufficient to inhibit transcription. J. Cell Biochem. 64: 390-402.

Gossen, M. and Bujard, H. 1995. Efficacy of tetracycline-controlled gene expression is influenced by cell type. Biotechniques 19: 213-216.

Hani, J., Schelbert, B., Bernhardt, A., Domdey, H., Fischer, G., Wiebauer, K., and Rahfeld, J.U. 1999. Mutations in a peptidylprolyl-cis/trans-isomerase gene lead to a defect in 3 '-end formation of a pre-mRNA in Saccharomyces cerevisiae. I. Biol. Chem. 274: 108-116.

Hirose, Y. and Manley, J.L. 2000. RNA polymerase II and the integration of nuclear events. Genes \& Dev. 14: 1415-1429.

Hirose, Y., Tacke, R., and Manley, J.L. 1999. Phosphorylated RNA polymerase II stimulates pre-mRNA splicing. Genes \& Dev. 13: 1234-1239.

Huang, S. and Spector, D.L. 1996. Intron-dependent recruitment of pre-mRNA splicing factors to sites of transcription. J. Cell Biol. 133: 719-732.

Izumi, T. and Maller, J.L. 1993. Elimination of cdc2 phosphorylation sites in the cdc25 phosphatase blocks initiation of M-phase. Mol. Biol. Cell 4: 1337-1350.

Kao, H.Y. and Siliciano, P.G. 1996. Identification of Prp40, a novel essential yeast splicing factor associated with the U1 small nuclear ribonucleoprotein particle. Mol. Cell. Biol. 16: 960-967.

Kleiman, F.E. and Manley, J.L. 2001. The BARD1-CstF-50 interaction links mRNA $3^{\prime}$ end formation to DNA damage and tumor suppression. Cell 104: 743-753.

Komarnitsky, P., Cho, E.J., and Buratowski, S. 2000. Different phosphorylated forms of RNA polymerase II and associated mRNA processing factors during transcription. Genes \& Dev. 14: 2452-2460.

Kops, O., Zhou, X.Z., and Lu, K.P. 2002. Pin1 modulates the dephosphorylation of the RNA polymerase II C-terminal domain by yeast Fcp1. FEBS Lett. 513: 305-311.

Kumagai, A. and Dunphy, W.G. 1996. Purification and molecular cloning of Plx1, a Cdc25-regulatory kinase from Xenopus egg extracts. Science 273: 1377-1380.

Lamond, A.I. and Spector, D.L. 2003. Nuclear speckles: A model for nuclear organelles. Nat. Rev. Mol. Cell. Biol. 4: 605-612.

Lee, T.H., Solomon, M.J., Mumby, M.C., and Kirschner, M.W. 1991. INH, a negative regulator of MPF, is a form of protein phosphatase 2A. Cell 64: 415-423.

Lin, P.S., Marshall, N.F., and Dahmus, M.E. 2002. CTD phosphatase: Role in RNA polymerase II cycling and the regulation of transcript elongation. Prog. Nucleic Acid Res. Mol. Biol. 72: 333-365.

Liou, Y.C., Ryo, A., Huang, H.K., Lu, P.J., Bronson, R., Fujimori, F., Uchida, T., Hunter, T., and Lu, K.P. 2002. Loss of Pin1 function in the mouse causes phenotypes resembling cyclin D1-null phenotypes. Proc. Nat1. Acad. Sci. 99: 1335-1340.

Long, J.J., Leresche, A., Kriwacki, R.W., and Gottesfeld, J.M. 
1998. Repression of TFIIH transcriptional activity and TFIIH-associated cdk7 kinase activity at mitosis. Mol. Cell. Biol. 18: 1467-1476.

Lu, K.P., Hanes, S.D., and Hunter, T. 1996. A human peptidylprolyl isomerase essential for regulation of mitosis. Nature 380: $544-547$.

Lu, H., Flores, O., Weinmann, R., and Reinberg, D. 1991. The nonphosphorylated form of RNA polymerase II preferentially associates with the preinitiation complex. Proc. Natl. Acad. Sci. 88: 10004-10008.

Lu, P.J., Zhou, X.Z., Shen, M., and Lu, K.P. 1999. Function of WW domains as phosphoserine- or phosphothreonine-binding modules. Science 283: 1325-1328.

Lu, K.P., Liou, Y.C., and Zhou, X.Z. 2002. Pinning down proline-directed phosphorylation signaling. Trends Cell Biol. 12: $164-172$.

Lu, P.J., Zhou, X.Z., Liou, Y.C., Noel, J.P., and Lu, K.P. 2002. Critical role of WW domain phosphorylation in regulating phosphoserine binding activity and Pin1 function. J. Biol. Chem. 277: 2381-2384.

Maniatis, T. and Reed, R. 2002. An extensive network of coupling among gene expression machines. Nature 416: 499506.

Manley, J.L. 2002. Nuclear coupling: RNA processing reaches back to transcription. Nat. Struct. Biol. 9: 790-791.

McCracken, S., Fong, N., Yankulov, K., Ballantyne, S., Pan, G., Greenblatt, J., Patterson, S.D., Wickens, M., and Bentley, D.L. 1997. The C-terminal domain of RNA polymerase II couples mRNA processing to transcription. Nature 385: 357-361.

Morris, D.P. and Greenleaf, A.L. 2000. The splicing factor, Prp40, binds the phosphorylated carboxyl-terminal domain of RNA polymerase II. J. Biol. Chem. 275: 39935-39943.

Morris, D.P., Phatnani, H.P., and Greenleaf, A.L. 1999. Phospho-carboxyl-terminal domain binding and the role of a prolyl isomerase in pre-mRNA 3 '-end formation. J. Biol. Chem. 274: $31583-31587$.

Myers, L.C. and Kornberg, R.D. 2000. Mediator of transcriptional regulation. Annu. Rev. Biochem. 69: 729-749.

Neubauer, G., Gottschalk, A., Fabrizio, P., Seraphin, B., Luhrmann, R., and Mann, M. 1997. Identification of the proteins of the yeast U1 small nuclear ribonucleoprotein complex by mass spectrometry. Proc. Nat1. Acad. Sci. 94: 385-390.

Orphanides, G. and Reinberg, D. 2002. A unified theory of gene expression. Cell 108: 439-451.

Parsons, G.G. and Spencer, C.A. 1997. Mitotic repression of RNA polymerase II transcription is accompanied by release of transcription elongation complexes. Mol. Cell. Biol. 17: 5791-5802.

Price, D.H. 2000. P-TEFb, a cyclin-dependent kinase controlling elongation by RNA polymerase II. Mol. Cell. Biol. 20: 26292634.

Ryo, A., Nakamura, M., Wulf, G., Liou, Y.C., and Lu, K.P. 2001. Pin1 regulates turnover and subcellular localization of $\beta$-catenin by inhibiting its interaction with APC. Nat. Cell Biol. 3: 793-801.

Schroeder, S.C., Schwer, B., Shuman, S., and Bentley, D. 2000. Dynamic association of capping enzymes with transcribing RNA polymerase II. Genes \& Dev. 14: 2435-2440.

Shen, M., Stukenberg, P.T., Kirschner, M.W., and Lu, K.P. 1998. The essential mitotic peptidyl-prolyl isomerase Pin1 binds and regulates mitosis-specific phosphoproteins. Genes \& Dev. 12: 706-720.

Shermoen, A.W. and O'Farrell, P.H. 1991. Progression of the cell cycle through mitosis leads to abortion of nascent transcripts. Cell 67: 303-310.
Shin, C. and Manley, J.L. 2002. The SR protein SRp38 represses splicing in M phase cells. Cell 111: 407-417.

Stukenberg, P.T. and Kirschner, M.W. 2001. Pin1 acts catalytically to promote a conformational change in Cdc25. Mol. Cell 7: 1071-1083.

Tacke, R. and Manley, J.L. 1995. The human splicing factors ASF/SF2 and SC35 possess distinct, functionally significant RNA binding specificities. EMBO J. 14: 3540-3551.

Verdecia, M.A., Bowman, M.E., Lu, K.P., Hunter, T., and Noel, J.P. 2000. Structural basis for phosphoserine-proline recognition by group IV WW domains. Nat. Struct. Biol. 7: 639643.

Wang, Y. and Prives, C. 1995. Increased and altered DNA binding of human p53 by S and G2/M but not G1 cyclin-dependent kinases. Nature 376: 88-91.

Whitfield, M.L., Zheng, L.X., Baldwin, A., Ohta, T., Hurt, M.M., and Marzluff, W.F. 2000. Stem-loop binding protein, the protein that binds the $3^{\prime}$ end of histone mRNA, is cell cycle regulated by both translational and posttranslational mechanisms. Mol. Cell. Biol. 20: 4188-4198.

Wu, X., Wilcox, C.B., Devasahayam, G., Hackett, R.L., ArevaloRodriguez, M., Cardenas, M.E., Heitman, J., and Hanes, S.D. 2000. The Ess 1 prolyl isomerase is linked to chromatin remodeling complexes and the general transcription machinery. EMBO J. 19: 3727-3738.

Wulf, G.M., Ryo, A., Wulf, G.G., Lee, S.W., Niu, T., Petkova, V., and Lu, K.P. 2001. Pin1 is overexpressed in breast cancer and cooperates with Ras signaling in increasing the transcriptional activity of c-Jun towards cyclin D1. EMBO $J$. 20: 3459-3472.

Xiao, S.H. and Manley, J.L. 1997. Phosphorylation of the ASF/ SF2 RS domain affects both protein-protein and proteinRNA interactions and is necessary for splicing. Genes \& Dev. 11: 334-344.

Yaffe, M.B., Schutkowski, M., Shen, M., Zhou, X.Z., Stukenberg, P.T., Rahfeld, J.U., Xu, J., Kuang, J., Kirschner, M.W., Fischer, G., et al. 1997. Sequence-specific and phosphorylation-dependent proline isomerization: A potential mitotic regulatory mechanism. Science 278 1957-1960.

Zeng, C., Kim, E., Warren, S.L., and Berget, S.M. 1997. Dynamic relocation of transcription and splicing factors dependent upon transcriptional activity. EMBO J. 16: 1401-1412.

Zhou, X.Z., Kops, O., Werner, A., Lu, P.J., Shen, M., Stoller, G., Kullertz, G., Stark, M., Fischer, G., and Lu, K.P. 2000. Pin1dependent prolyl isomerization regulates dephosphorylation of Cdc25C and tau proteins. Mol. Cell 6: 873-883. 


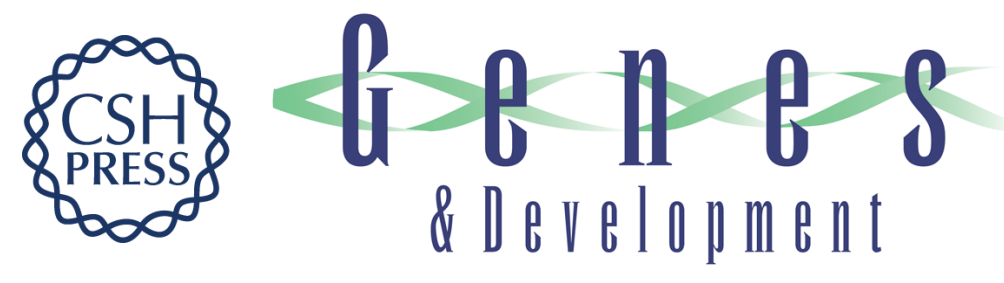

\section{Pin1 modulates the structure and function of human RNA polymerase II}

Yu-Xin Xu, Yutaka Hirose, Xiao Zhen Zhou, et al.

Genes Dev. 2003, 17:

Access the most recent version at doi:10.1101/gad.1135503

References This article cites 61 articles, 34 of which can be accessed free at: http://genesdev.cshlp.org/content/17/22/2765.full.html\#ref-list-1

License

Email Alerting

Receive free email alerts when new articles cite this article - sign up in the box at the top Service right corner of the article or click here.

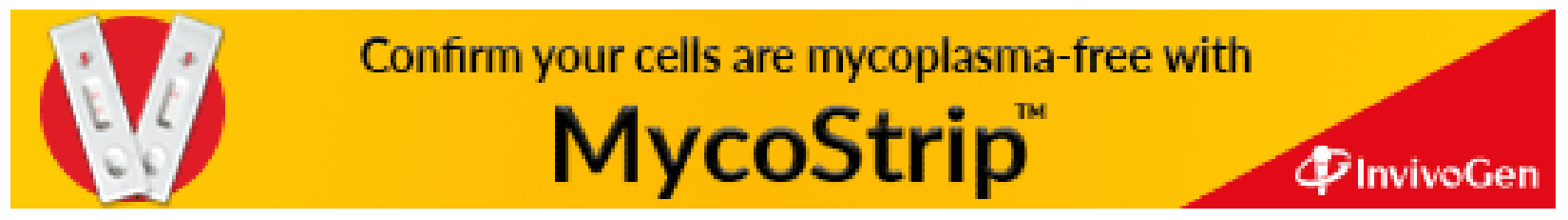

